Figure 2. DAS28 at 24 weeks-All TIMs were more likely to achieve remission compared to cDMARD, but tocilizumab IV and SC had a greater magnitude of effect ${ }^{\star}$

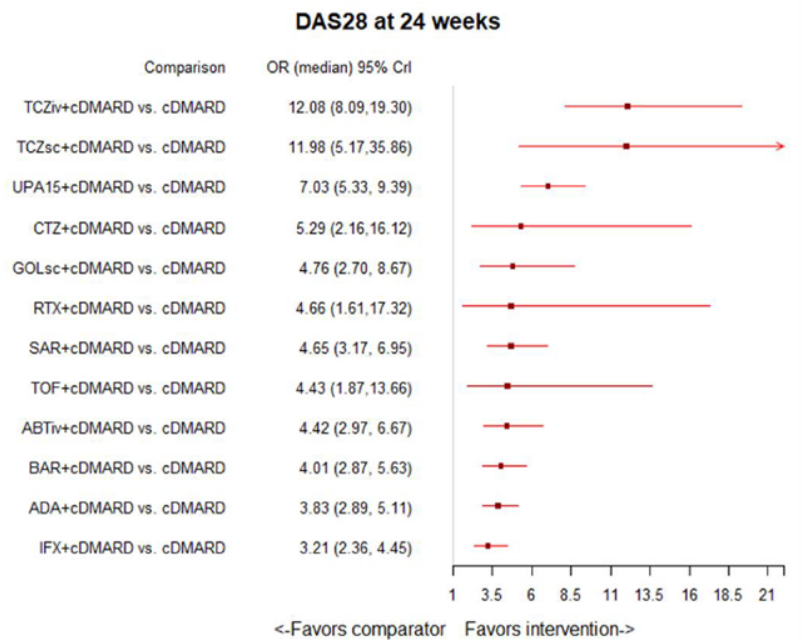

Abbreviations- ABT: Abatacept, ADA: Adalimumab, cDMARD: BAR: Baricitinib, Conventional Disease-modifying Antirheumatic Drugs, CTZ: Certolizumab pegol, Crl: credible interval, GOL: Golimumab, IFX: Infliximab, iv: Untravenous, RTX: R

- $95 \%$ Crls that do not overlap with 1 are statistically significant

DMARDs are defined as systemic agents with broad immunomodulatory effects like methotrexate, leflunomide,

hydroxychloroquine, and sulfasalazine.

Acknowledgments: This study was sponsored and funded by Genentech, Inc. Disclosure of Interests: Jennie H. Best Shareholder of: Genentech, Inc., Employee of: Genentech, Inc., Jennifer Uyei: None declared, Joseph Dang Shareholder of: Genentech, Inc., Employee of: Genentech, Inc., Yilin Jiang: None declared, Rajpal Singh: None declared, Pinar Bilir: None declared, Andreas Karabis: None declared, Julie Munakata: None declared, William Reiss Shareholder of: Genentech, Inc., Employee of: Genentech, Inc.

DOI: 10.1136/annrheumdis-2020-eular.533

\section{AB0276 DIFFERENCES BETWEEN IMPACT OF BIOLOGICAL THERAPY AND IMPACT OF CONVENTIONAL TREATMENT ON PRODUCTIVITY AND QUALITY OF LIFE IN PATIENTS WITH RHEUMATOID ARTHRITIS}

M. Bogojevic ${ }^{1}$, N. Miketic ${ }^{1}$, S. Aligrudic ${ }^{2}$, R. Medjedovic ${ }^{1}$, D. Loncar ${ }^{3}$, A. Bulatovic ${ }^{1} .{ }^{1}$ Clinical Center of Montenegro, Clinic of Internal Medicine, Rheumatology Department, Podgorica, Montenegro; ${ }^{2}$ Mercur Nera Polyclinic, Podgorica, Montenegro; ${ }^{3}$ Faculty of Economics, University of Belgrade, Podgorica, Montenegro

Background: Number of patients with rheumatoid arthritis in Montenegro amounts around 3,000 , while $8 \%$ of them are on biological therapy. This percent is similar, or even higher in comparison to countries that are highly comparable to Montenegro. However, the percentage is still lower than in European countries.

Objectives: Objective of the study was to identify the differences between impact of biological and conventional therapy on quality of life of RA patients, their work ability and productivity, mental health, emotional state and social inclusion.

Methods: The analysis was based on data gathered from the questionnaires filled by RA patients in Montenegro: 92 patients treated with biological therapy and 78 treated with conventional therapy. More insights and information from examined patients were gathered on two focus groups. Following indicators were used in the study: two indicators that measure work ability and productivity: one monetized - Work Productivity and Activity Impairment Questionnaire General Health V2.0 (WPAI-GH) and one non-monetized - RA Work Instability Scale (RA WIS), and two indicators that measure quality of life - Health Assessment Questionnaire (HAQ-DI) and RAND 36-Item Health Survey (SF-36).

Results: WPAI-GH results are used in evaluation of absenteeism and presentism costs per RA patient per annum, which are caused exclusively by rheumatoid arthritis. WPAI-GH results are presented in the following figure. Total cost of absenteeism and presenteeism of RA patients in Montenegro amounts to 3.8 million EUR per annum. Results of RA WIS indicator suggest that patients treated with biological therapy are characterized by low to moderate level of work instability, and patients treated with conventional therapy by moderate level. Patients treated with biological therapy have shown $25 \%$ lower level of work instability. HAQ-DI indicator shows that both groups of patients are characterized by mild difficulties to moderate disability in performing everyday activities. However, patients treated with conventional therapy deal with higher level of difficulties, even though their level of RA progression is lower, on average. SF-36 indicator shows that patients treated with conventional therapy have lower level of physica functioning, followed by $26 \%$ higher pain intensity. They are $25 \%$ more exposed to limitations due to physical health problems caused by RA, and $20 \%$ more to limitations due to emotional problems. Patients treated with biological therapy, on average, rate their health with $50 \%$ higher rank in comparison to subjective health rate of patients treated with conventional therapy. They also feel that their health has improved during the past year, or stayed approximately the same, while patients treated with conventional therapy feel that their health condition has aggravated, or stayed unchanged.

Conclusion: Results show that health condition, emotional state and life quality are better among the patients treated with biological therapy. Also, their productivity is higher compared to patients treated with conventional therapy. This conclusion is additionally supported by the fact that there is more progression of disease among RA patients treated with biological therapy, as well as by the fact that the average duration of RA is almost two times longer among examinees who are on biological therapy than among examinees who are on conventiona therapy. Accordingly, access to biological therapy for greater number of patients in earlier stage of disease would result in reduction costs of lost productivity and work disability connected to RA, as well as in mitigation of RA impact on lives and functionality of patients.

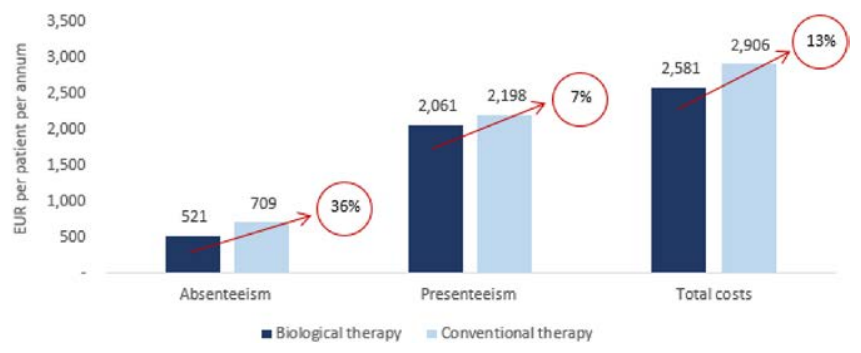

Figure 1. WPAI-GH

Disclosure of Interests: None declared

DOI: 10.1136/annrheumdis-2020-eular.5569

\section{\begin{tabular}{|l|l}
\hline AB0277 & PREVALENCE OF HEPATITIS MARKERS IN PATIENTS
\end{tabular} TREATED WITH BIOLOGICAL DISEASE-MODIFYING ANTIRHEUMATIC DRUGS: RESULTS OF THE TUNISIAN REGISTRY BINAR}

A. Fazaa ${ }^{1}$, H. Boussaa ${ }^{1}$, S. Miladi ${ }^{1}$, K. Ouenniche ${ }^{1}$, L. Souabni ${ }^{1}$, S. Kassab ${ }^{1}$, S. Chekili ${ }^{1}$, K. Ben Abdelghani ${ }^{1}$, L. Abdelmoula ${ }^{2}$, S. Baklouti ${ }^{3}$, N. Bergaoui ${ }^{4}$, E. Bouajina ${ }^{5}$, M. Elleuch ${ }^{6}$, I. Gharsallah ${ }^{7}$, Y. Mohamed ${ }^{8}$, M. M. Kchir ${ }^{9}$, S. Kochbati ${ }^{10}$, A . Laatar ${ }^{1} .{ }^{1}$ Mongi Slim Hospital, Rheumatology, Tunis, Tunisia; ${ }^{2}$ Charles Nicolle Hospital, Rheumatology, Tunis, Tunisia; ${ }^{3}$ Hedi Chaker Hospital, Rheumatology, Sfax, Tunisia; ${ }^{4}$ Fattouma Bourguiba Hospital, Rheumatology, Monastir, Tunisia; ${ }^{5}$ Farhat Hached Hospital, Rheumatology, Sousse, Tunisia; ${ }^{6} \mathrm{La}$ Rabta Hospital, Rheumatology, Tunis, Tunisia; ${ }^{7}$ Military Hospital, Rheumatology, Tunis, Tunisia; ${ }^{8}$ Tahar Sfar Hospital, Rheumatology, Mahdia, Tunisia; ${ }^{9}$ Mohamed Kassab Institute of Orthopedics, Rheumatology, Tunis, Tunisia; ${ }^{10} \mathrm{Hbib}$ Thameur Hospital, Rheumatology, Tunis, Tunisia

Background: In the recent decades, biological disease-modifying antirheumatic drugs (bDMARDs) have significantly improved management and quality of life in patients with rheumatoid arthritis (RA) and spondyloarthritis (SpA).

However, bDMARDs have also a strong influence on the immune system, leading to a risk of serious infection. Reactivation of hepatitis $B(\mathrm{HBV})$ and $C(\mathrm{HCV})$ virus is one of the most redoubtable complications of these immunosuppressive agents.

Objectives: The aims of this study were to determine the screening rate for hepatitis $B$ and $C$ before starting a biological treatment and to examine the prevalence of their markers in patients with RA or SpA.

Methods: Our study evaluated all patients included in the Tunisian registry BINAR (Biologic National Registry) since 2018 who had RA (ACR/EULAR 2010) or SpA (ASAS criteria) aged with more than eighteen years old and receiving their first bDMARDs during the two past years.

The following information were retrieved from the registry: demographic data on the patients, disease parameters, medication, HBV surface antigen (HBs Ag), antibody to HBs Ag (Anti HBs), antibody to HBV core antigen (Anti HBc), HBVDNA, antibody to HCV (anti HCV) status and liver function tests (AST: aspartate aminotransferase; ALT:alanine aminotransferase)

Results: A total of 298 patients was included, 111 men and 178 women, with a mean age of $49.2 \pm 14.1$ years old [18-79]. Among them, $58.7 \%$ were 